\title{
Steroids augment relengthening of contracted airway smooth muscle: potential additional mechanism of benefit in asthma
}

\author{
O.J. Lakser*, M.L. Dowell*, F.L. Hoyte*, ${ }^{\star}$, B. Chen", T.L. Lavoie ${ }^{\#}$, C. Ferreira", \\ L.H. Pinto", N.O. Dulin ${ }^{\#}$, P. Kogut ${ }^{\#}$, J. Churchill ${ }^{\#}$, R.W. Mitchell ${ }^{\#,+}$ and J. Solway ${ }^{\#,+}$
}

ABSTRACT: Breathing (especially deep breathing) antagonises development and persistence of airflow obstruction during bronchoconstrictor stimulation. Force fluctuations imposed on contracted airway smooth muscle (ASM) in vitro result in its relengthening, a phenomenon called force fluctuation-induced relengthening (FFIR). Because breathing imposes similar force fluctuations on contracted ASM within intact lungs, FFIR represents a likely mechanism by which breathing antagonises bronchoconstriction. While this bronchoprotective effect appears to be impaired in asthma, corticosteroid treatment can restore the ability of deep breaths to reverse artificially induced bronchoconstriction in asthmatic subjects. It has previously been demonstrated that FFIR is physiologically regulated through the p38 mitogen-activated protein kinase (MAPK) signalling pathway. While the beneficial effects of corticosteroids have been attributed to suppression of airway inflammation, the current authors hypothesised that alternatively they might exert their action directly on ASM by augmenting FFIR as a result of inhibiting p38 MAPK signalling.

This possibility was tested in the present study by measuring relengthening in contracted canine tracheal smooth muscle (TSM) strips.

The results indicate that dexamethasone treatment significantly augmented FFIR of contracted canine TSM. Canine tracheal ASM cells treated with dexamethasone demonstrated increased MAPK phosphatase-1 expression and decreased p38 MAPK activity, as reflected in reduced phosphorylation of the p38 MAPK downstream target, heat shock protein 27.

These results suggest that corticosteroids may exert part of their therapeutic effect through direct action on airway smooth muscle, by decreasing p38 mitogen-activated protein kinase activity and thus increasing force fluctuation-induced relengthening.

KEYWORDS: Asthma, bronchoconstriction, bronchoprotection, deep breaths, steroids, tidal breathing

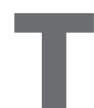

idal breathing, especially with larger tidal volumes, antagonises the development and persistence of airflow obstruction during bronchoconstrictor stimulation in normal animals and humans [1-6]. However, this bronchoprotective effect is impaired in individuals suffering from asthma $[5,7,8]$. Corticosteroids have long been a mainstay in asthma therapy. These agents reduce airway constrictor hyperresponsiveness in mice with experimental allergen-induced airway inflammation $[9,10]$ and improve or restore the bronchodilatory effect of deep inspiration that is typically impaired in asthmatic patients [11-13]. The mechanisms by which breathing confers this beneficial effect in

For editorial comments see page 1135. normal individuals and how corticosteroids restore this effect in asthmatic individuals are not clear. The current authors propose a potential mechanism by which breathing antagonises bronchoconstriction and suggest a novel hypothesis of how corticosteroids may restore this effect.

It is known that superimposing load fluctuations (that mimic those generated by breathing) upon isotonically contracted tracheal smooth muscle (TSM) strips causes them to relengthen [14-16], a phenomenon termed force fluctuation-induced relengthening (FFIR). It has been proposed that FFIR may be one mechanism by which breathing antagonises bronchoconstriction. Importantly, FFIR can be physiologically regulated, since pharmacological inhibition of actin polymerisation [17] or p38

\section{AFFILIATIONS}

Depts of *Paediatrics and

\# Medicine, Section of Pulmonary and Critical Care Medicine, University of Chicago, Chicago, and "Dept of Neurobiology and Physiology, Northwestern University, Evanston, IL, USA.

${ }^{+}$Both authors contributed equally to this article.

\section{CORRESPONDENCE}

0.J. Lakser

Dept of Paediatrics

University of Chicago

MC4064

5841 S. Maryland Avenue

Chicago

IL 60637

USA

Fax: 17738341444

E-mail: olakser@

peds.bsd.uchicago.edu

Received:

June 182008

Accepted after revision:

August 152008

SUPPORT STATEMENT

This study was supported by National Institutes of Health grants HL 79368 , Al 56352 and HD 043387.

STATEMENT OF INTEREST

A statement of interest for J. Solway can be found at

www.erj.ersjournals.com/misc/ statements.shtml 
mitogen-activated protein kinase (MAPK) signalling [14] augments FFIR in vitro.

In general, the beneficial effects of corticosteroids have been attributed to their anti-inflammatory actions, as pro-inflammatory cytokines can modulate airway smooth muscle (ASM) contractile and relaxant function. HAKONARSON et al. [18] have shown that interleukin (IL)-1 $\beta$ and tumour necrosis factor (TNF)- $\alpha$ increase ASM contractility to acetylcholine (ACh) and impair ASM relaxation with isoproterenol, changes prevented when ASM is pre-treated with dexamethasone. However, dexamethasone also increases relaxation with $\mathrm{KCl}$ [19] and isoproterenol [20] in contracted TSM even in the absence of a pro-inflammatory environment, suggesting that corticosteroids might exert direct effects on ASM contraction independent of their anti-inflammatory effect. However, since these studies were conducted on rabbit tracheal and bronchial ring segments with intact epithelium, corticosteroids may have exerted their effect indirectly by acting on the epithelium or mucosa rather than on the smooth muscle itself. Corticosteroids have also been reported to induce expression of MAPK phosphatase (MKP)-1, which dephosphorylates and inactivates p38 MAPK [21], as well as other MAP kinases [22, 23]. Since pharmacological inhibition of p38 MAPK enhances FFIR [14], the current authors reasoned that corticosteroid treatment might augment FFIR as well. Indeed, in the present study, dexamethasone treatment was found to increase FFIR of contracted canine trachealis strips (epithelium removed) in vitro, and such treatment increased MKP-1 expression in cultured canine tracheal myocytes. The latter was accompanied by decreased p38 MAPK activity, as reflected in diminished phosphorylation of heat shock protein (HSP)27, a well-established downstream target of p38 MAPK [24]. Together, these results suggest that FFIR contributes to the bronchoprotective effect of breathing and that corticosteroid treatment may restore this effect in asthma by augmenting FFIR via reduction of p38 MAPK activation.

\section{METHODS}

\section{Assessment of FFIR of ACh-contracted canine TSM strips}

In accordance with Institutional Animal Care and Use Committee approved protocols, random source dogs were anaesthetised and killed by overdose with pentobarbital sodium $\left(30 \mathrm{mg} \cdot \mathrm{kg}^{-1}\right.$ i.v.). Tracheas were excised and rinsed several times in Krebs-Henseleit $(\mathrm{K}-\mathrm{H})$ solution $(115 \mathrm{mM}$ $\mathrm{NaCl}, 25 \mathrm{mM} \mathrm{NaCO}, 1.38 \mathrm{mM} \mathrm{KH}_{2} \mathrm{PO}_{4}, 2.51 \mathrm{mM} \mathrm{KCl}$, $2.46 \mathrm{mM} \mathrm{MgCl} 2,2.5 \mathrm{mM} \mathrm{CaCl}_{2}$ and $11.2 \mathrm{mM}$ dextrose). $\mathrm{K}-\mathrm{H}$ was gassed with $95 \% \mathrm{O}_{2} / 5 \% \mathrm{CO}_{2}$ to maintain a $\mathrm{pH}$ between 7.3 and 7.5. Some tissues were stored for up to 4 days at $4{ }^{\circ} \mathrm{C}$ prior to study, without apparent effect on results. All studies were conducted at $37^{\circ} \mathrm{C}$ in $\mathrm{K}-\mathrm{H}$ solution. As described previously [17], parallel-fibred bundles of canine TSM (CTSM) were dissected free of all overlying connective tissue and epithelium and fastened at either end in aluminium foil clips (Laser Services Inc., Westford, MA, USA). The strips were then placed in a horizontal dip-tray style of organ bath and connected to a 300B lever arm/force transducer (Aurora Scientific, Aurora, Canada); the 300B lever arm measures both force output and length changes. All force and length changes of the TSM strips were monitored using Powerlab Chart software (ADInstruments, Colorado Springs, CO, USA).
As described previously [17], after equilibration, reference length (Lref) of the tissues measured between 3.5 and $6.0 \mathrm{~mm}$ and maximal response (Fmax) to $100 \mu \mathrm{M}$ ACh was determined. Lref and Fmax in response to $\mathrm{ACh}$ were then used as base parameters for force oscillation contraction sequences. Muscles were allowed to relax by re-perfusing with $\mathrm{K}-\mathrm{H}$ alone. Tissues were re-exposed to $100 \mu \mathrm{M}$ ACh $20 \mathrm{~min}$ after force reached relaxed baseline, and allowed to shorten isotonically against an afterload of $32 \%$ Fmax for $20 \mathrm{~min}$ and then without delay and during continued ACh exposure, force oscillations were superimposed (frequency $0.2 \mathrm{~Hz}$, amplitude $\pm 16 \%$ Fmax) for $20 \mathrm{~min}$; thereafter, TSM strips were allowed to relax by switching to ACh-free $\mathrm{K}-\mathrm{H}$ solution. All length changes were noted. Next, tissues were incubated for $\sim 2 \mathrm{~h}$ in $\mathrm{K}-\mathrm{H}$ solution containing $4 \mu \mathrm{M}$ dexamethasone or vehicle control. This concentration was chosen based on studies performed on a separate cohort of TSM strips that showed it to have minimal effects on isometric force (data not shown). After this equilibration period, the entire isotonic contraction sequence was repeated in the continued presence of dexamethasone or vehicle; length changes during contractions before and after inhibitor treatment were expressed as percentage of Lref. FFIR was calculated as the extent of relengthening from the end of the isotonic shortening period until the end of the oscillation period. Differences between the first and second isotonic/force oscillation sequence (i.e. before and after dexamethasone or vehicle) were expressed as $\Delta$ FFIR.

\section{Assessment of MKP-1 expression and HSP27 phosphorylation in cultured CTSM cells}

Since it was previously found that the inhibition of p38 MAPK augmented FFIR [14] and that corticosteroids induce the expression of dual-specific phosphatases, especially MKP-1 [21-23], which in turn dephosphorylates and inactivates p38 MAPK [21], MKP-1 expression and HSP27 phosphorylation (a downstream target of p38 MAPK) were measured in CTSM cells. Airway myocytes were dissociated from adult canine trachealis and cultured using previously described methods $[25,26]$. Briefly, TSM cells were enzymatically digested from dissected trachealis using $10 \mathrm{U} \cdot \mathrm{mL}^{-1}$ elastase, $600 \mathrm{U} \cdot \mathrm{mL}^{-1}$ collagenase and $2 \mathrm{U} \cdot \mathrm{mL}^{-1}$ Nagarse protease. Myocytes were grown on uncoated plastic culture plates in Dulbecco's modified Eagle medium/F12 supplemented with 10\% foetal bovine serum, $50 \mathrm{U} \cdot \mathrm{mL}^{-1}$ penicillin, $50 \mu \mathrm{g} \cdot \mathrm{mL}^{-1}$ streptomycin and $50 \mu \mathrm{g} \cdot \mathrm{mL}^{-1}$ gentamicin. Low passage (1-3) myocytes from five different primary cell lines were treated with $4 \mu \mathrm{M}$ dexamethasone (or in media alone as untreated control) for 1 or $2 \mathrm{~h}$. Protein lysates from treated and untreated myocytes were collected using CelLytic lysis/extraction buffer (SigmaAldrich Co., St Louis, MO, USA). Following the manufacturer's protocol, the cells were washed with PBS, lysed for $15 \mathrm{~min}$ with $0.5 \mathrm{~mL}$ lysis buffer supplemented with Complete protease inhibitor cocktail mix (Roche, Basel, Switzerland), then centrifuged to pellet the cellular debris. The protein containing supernatant was then used for western blots.

Proteins from dexamethasone- and vehicle-treated CTSM cells were extracted as described previously [17, 27]. All lanes in all gels were loaded with equal volumes and concentrations of total protein extracts. Denatured proteins were separated by SDS-polyacrylamide gel electrophoresis (NuPage $4-12 \%$ gels; Invitrogen, Carlsbad, CA, USA), transferred to Immobilin-P 

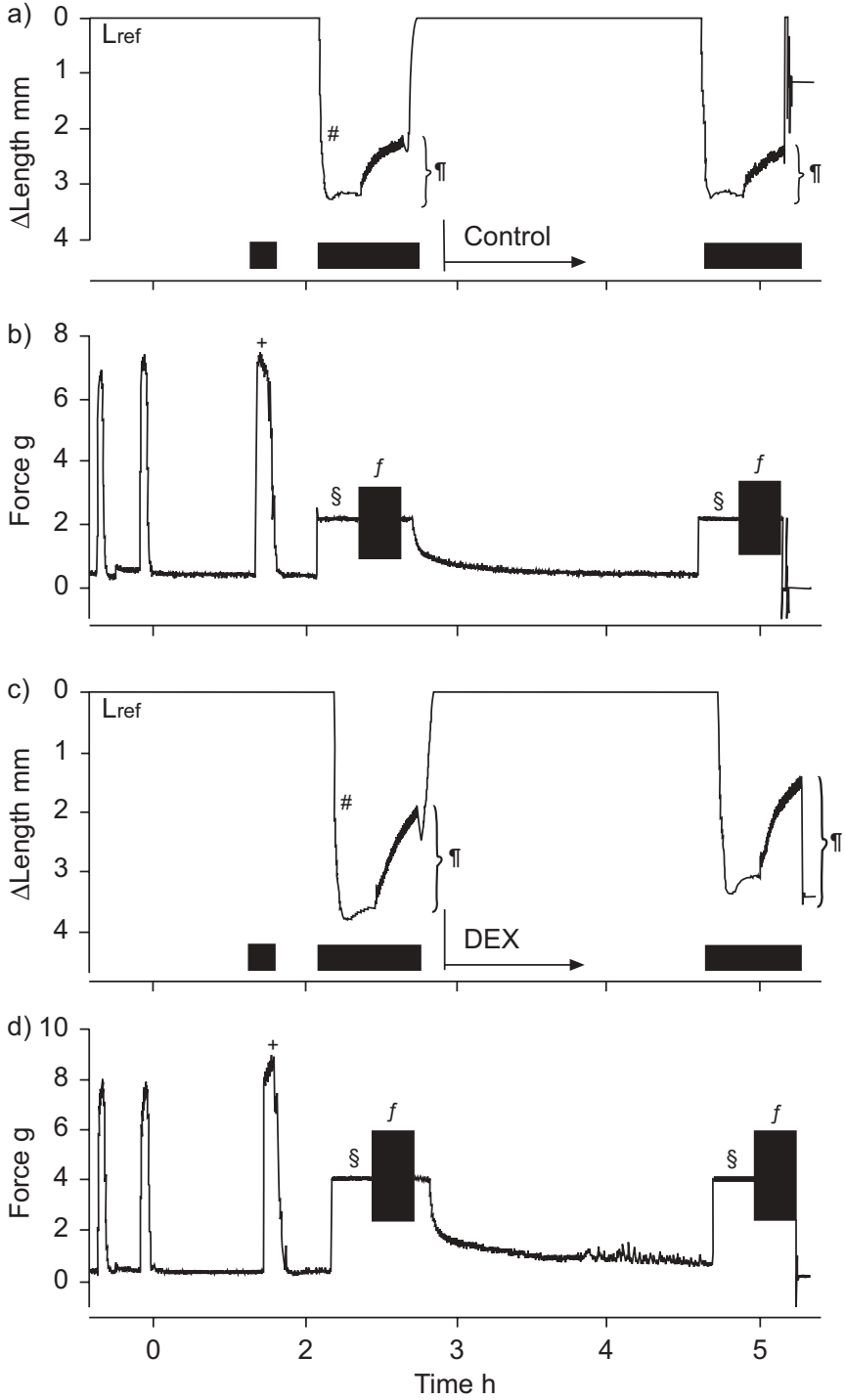

FIGURE 1. Experimental protocol to assess drug effect on force fluctuationinduced relengthening (FFIR). Changes $(\Delta)$ in length ( $a$ and $c$ ) and force (b and d) of tracheal smooth muscle (TSM) strips were measured. TSM strips were attached to a force/length transducer and equilibrated allowing for determination of reference length (Lref) and isometric maximal force $\left(\mathrm{Fmax}^{+}{ }^{+}\right.$) upon exposure to $100 \mu \mathrm{M}$ acetylcholine (Ach; $\boldsymbol{\text { in }}$ a and c). For the next exposure to ACh, TSM strips were contracted against a load equal to $32 \%$ of established $F \max (\$)$, thus producing isotonic shortening $\left({ }^{\#}\right)$. At 20 min into the isotonic contraction, sinusoidal force fluctuations $(0.2 \mathrm{~Hz}$ to simulate tidal breathing) were superimposed on $32 \%$ Fmax that were of amplitude $\pm 16 \% \mathrm{Fmax}\left({ }^{f}\right)$. FFIR (") was noted at the end of $20 \mathrm{~min}$. ACh was again washed out and baseline force and Lref re-established. TSM was then incubated for $\sim 2 \mathrm{~h}$ in vehicle (Control; $\mathrm{a}$ and $\mathrm{b}$ ) or $4 \mu \mathrm{M}$ dexamethasone (DEX; $\mathrm{c}$ and d). Differences in FFIR post- versus pre-treatment were compared.

polyvinylidene difluoride membranes (Millipore Corporation, Medford, MA, USA), and probed for phosphorylated and nonphosphorylated HSP27, MKP-1 and $\beta$-actin. Phosphorylated and nonphosphorylated HSP27 were detected on the same gels using Pierce SuperSignal West Pico chemiluminescent substrate (Thermo Fisher Scientific Inc., Rockford, IL, USA). Membranes initially probed for phosphorylated HSP27 were stripped for $30 \mathrm{~min}$ at $50^{\circ} \mathrm{C}(0.76 \%$ Tris base, $2 \%$ SDS, $0.7 \%$

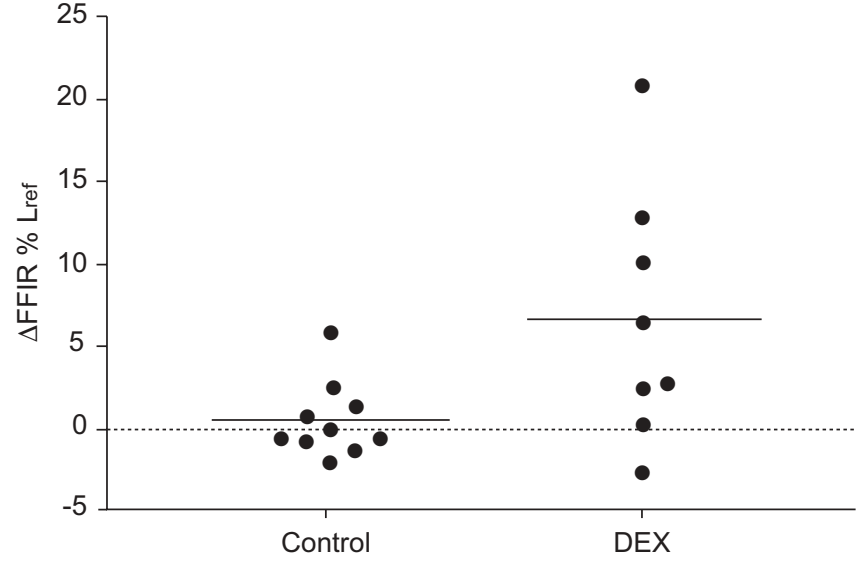

FIGURE 2. Cumulative data for force fluctuation-induced relengthening (FFIR) in control and dexamethasone (DEX)-treated canine tracheal smooth muscle strips. DEX-treated strips demonstrated a greater increase in FFIR $(\Delta \mathrm{FFIR})$, expressed as $\%$ of reference length (Lref), than control strips when comparing FFIR post-treatment with pre-treatment.

$\beta$-mercaptoethanol, $\mathrm{pH}$ 6.7) and re-probed for total HSP27. Blot intensities (volumes) were calculated using a BioRad S710 densitometer and software (Bio-Rad Laboratories Inc., Hercules, CA, USA). The ratios of phosphorylated to total HSP27 and MKP-1 to $\beta$-actin expression were assessed relative to data derived for vehicle-treated cells, on the same western blot. All primary antibodies were raised in rabbits, except for $\beta$-actin (which was raised in mice), and were from the following sources: HSP27 was a gift from W.T. Gerthoffer (Dept of Biochemistry, University of South Alabama, Mobile, AL, USA); phosphorylated HSP27 was from Stressgen Bioreagents (Assay Designs Inc., Ann Arbor, MI, USA); antiMKP-1 was from Santa Cruz Biotechnology Inc. (Santa Cruz, CA, USA); and anti- $\beta$-actin was from Sigma-Aldrich Co.

\section{Data analysis}

All data were expressed as mean \pm SE. Results from the control and dexamethasone-treated groups were compared with unpaired t-tests. Significant differences were defined when $\mathrm{p}<0.05$.

\section{RESULTS}

\section{FFIR in CTSM strips}

Superimposition of force fluctuations upon a steady load against which ACh-stimulated CTSM strips had shortened caused them to relengthen (fig. 1). After dexamethasone treatment, CTSM strips demonstrated significantly increased FFIR, whereas no change in FFIR was observed in vehicletreated CTSM strips; the increase in FFIR ( $\triangle$ FFIR) was significantly larger in dexamethasone-treated trachealis strips than in control strips $(6.6 \pm 2.70 \%$ versus $0.52 \pm 0.72 \%$ change, respectively; $\mathrm{p}=0.029$; fig. 2 ). Isotonic shortening post-treatment was not different in dexamethasone- and vehicle-treated tissues $(94.65 \pm 2.59$ versus $96.32 \pm 4.44 \%$ of initial shortening, respectively; $\mathrm{p}=0.737$; fig. 3 ), so this parameter could not account for the differences observed in $\triangle F F I R$ in dexamethasonetreated TSM. 


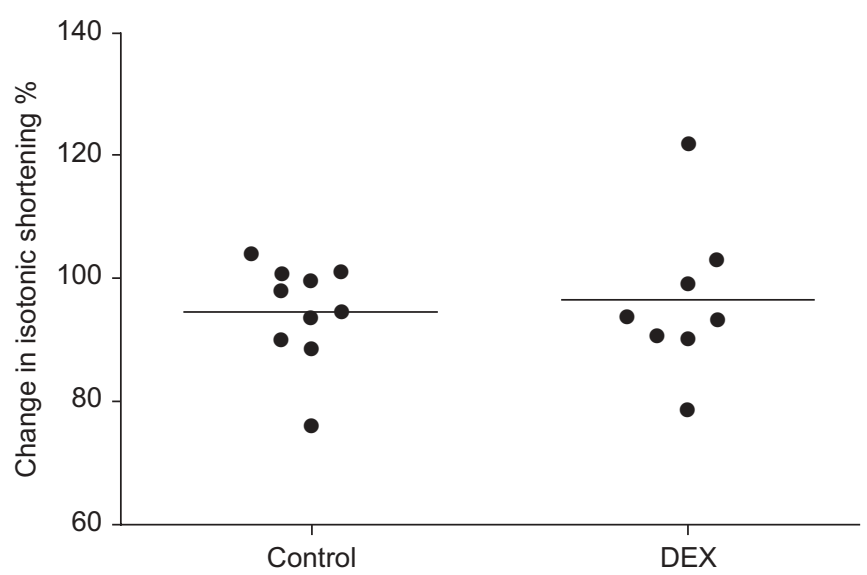

FIGURE 3. Cumulative data for isotonic shortening of control and dexamethasone (DEX)-treated canine tracheal smooth muscle strips. There was no significant difference in the change in isotonic (no oscillations) shortening after treatment, between control and DEX-treated tissues.

\section{CTSM cell culture experiments}

CTSM cells incubated in $4 \mu \mathrm{M}$ dexamethasone demonstrated significantly increased MKP-1 expression within $1 \mathrm{~h}$ compared with control cells $(1.69 \pm 0.23$ versus 1.00 , respectively; $p=0.040$ fig. $4 \mathrm{a}$ and $\mathrm{c})$. Although at $1 \mathrm{~h}$ there was no difference in HSP27 phosphorylation between dexamethasone-treated cells and control cells, by $2 \mathrm{~h}$, cells treated with dexamethasone demonstrated a significant decrease in HSP27 phosphorylation, compared with control cells $(0.54 \pm 0.10$ versus 1.00 , respectively; $p=0.041$; fig. $4 b$ and $d$ ).

\section{DISCUSSION}

The present study demonstrated enhancement of FFIR of AChcontracted TSM strips by treatment with corticosteroids, a class of drugs that also augments the ability of deep breaths to reverse bronchoconstriction in people with asthma. Application of large force-fluctuations resulted in significant relengthening of isotonically shortened smooth muscle strips, and dexamethasone treatment further enhanced this effect. Therefore, it seems possible that corticosteroids might help restore the bronchodilatory effect of deep inspiration in asthmatic patients [11-13] in part by enhancing FFIR in their ASM.

Dexamethasone might conceivably affect smooth muscle FFIR by a number of mechanisms. Corticosteroids are potent antiinflammatory agents. Dexamethasone decreases bronchoconstriction in sensitised animals $[9,10]$ and enhances the bronchodilatory effect of deep inspiration in asthmatic individuals [11-13]. In the present study, it seems less likely that dexamethasone influenced FFIR through an anti-inflammatory action, as the TSM strips used were obtained from nonsensitised, healthy dogs. However, length oscillations applied to bovine smooth muscle strips have been found to induce the expression of IL-6 and IL-8 genes, and this a)

MKP-1

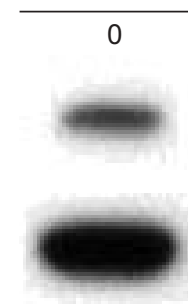

DEX exposure h
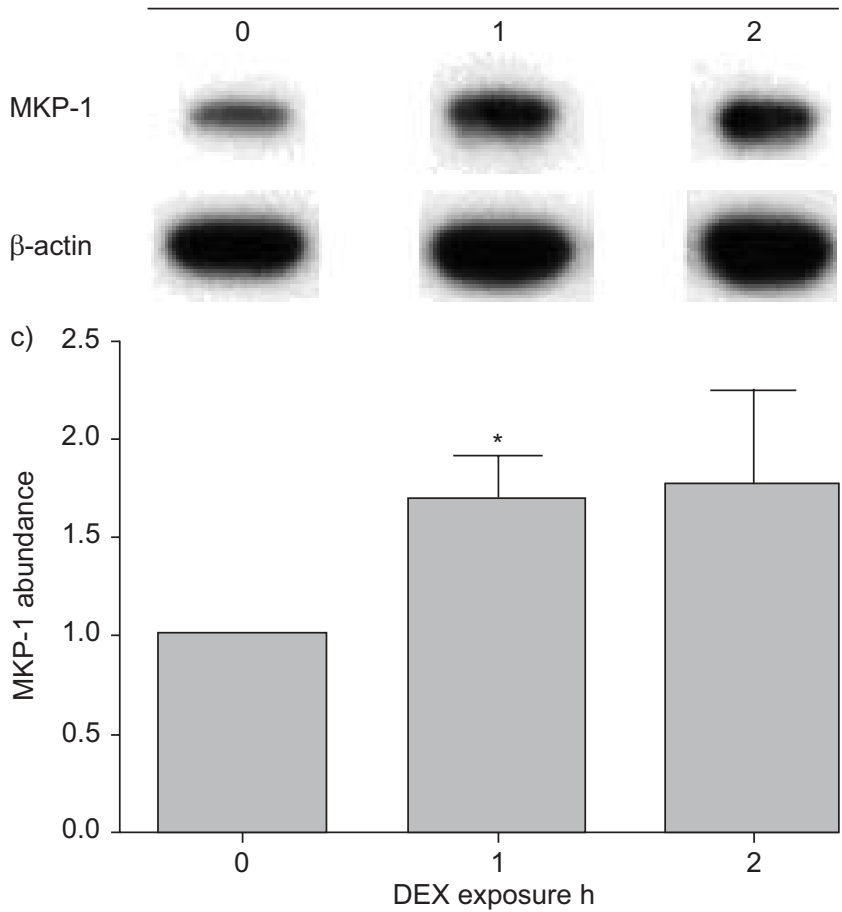

b)

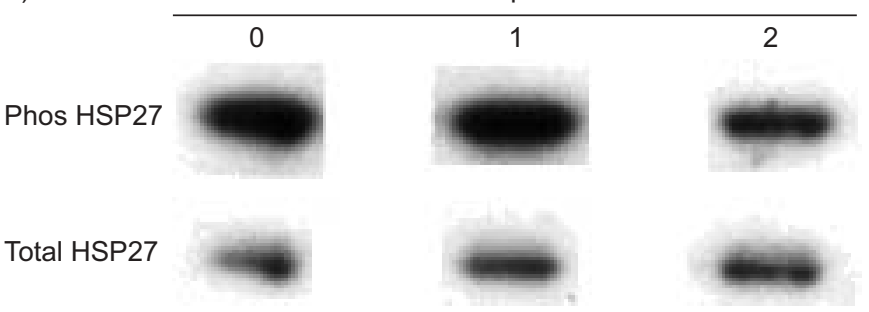

d)

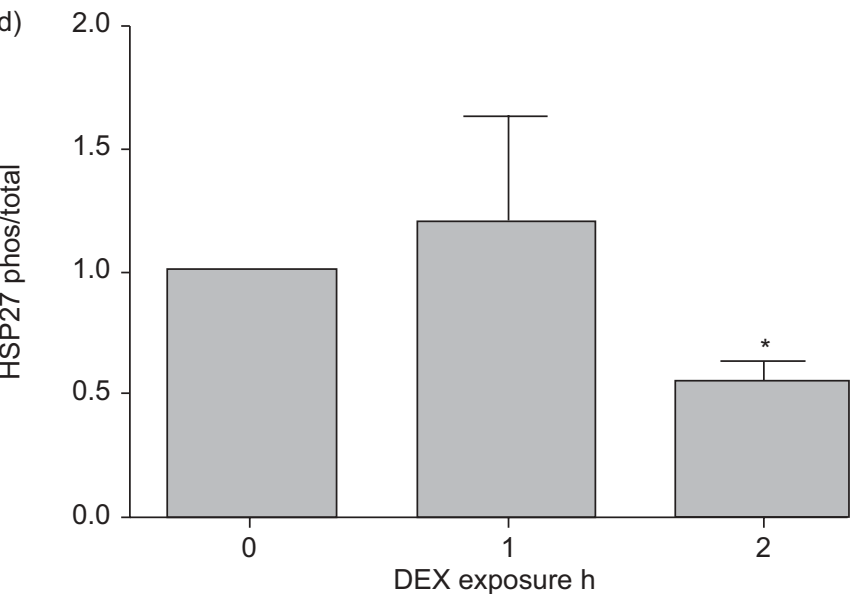

FIGURE 4. Mitogen-activated protein kinase phosphatase (MKP)-1 (a and c) and heat shock protein (HSP)27 (b and d) expression in dexamethasone (DEX)-treated canine tracheal smooth muscle (TSM) cells, shown as western blots ( $a$ and b) and quantitatively ( $c$ and d). After $1 \mathrm{~h}$ of incubation in $4 \mu \mathrm{M}$ DEX, TSM cells demonstrated a significant increase in MKP-1 expression (relative to $\beta$-actin) compared with control (0 h DEX) cells. Although HSP27 phosphorylation (phos; relative to total HSP27) was unchanged at $1 \mathrm{~h}$ incubation, by $2 \mathrm{~h}$ there was significantly less HSP27 phosphorylation in cells incubated in DEX compared with control (0 h DEX) cells. Molecular weights: HSP27, total and phosphorylated $\sim 27 \mathrm{kD}$; MKP-1 and $\beta$-actin $\sim 40 \mathrm{kD}$. *: $\mathrm{p}<0.05$ 
expression is reduced when the frequency of oscillations is reduced [28]. Other studies using cultured cells and mechanical stretch/strain have shown similar results [29, 30]. In cultured human ASM cells, corticosteroids reduce TNF- $\alpha$ induced IL- 6 release from cultured ASM cells by upregulation of MKP-1 [31]. These data raise the possibility that the reduction of cytokine release from ASM itself by corticosteroids may be involved in their enhancement of FFIR.

Dexamethasone has multiple effects on smooth muscle function [32], which include reducing intracellular calcium [33], uncoupling of $\mathrm{H} 1$ histamine receptors [34] and reducing muscarinic receptor expression [35]. Together, these effects could act in concert to reduce smooth muscle contractile activation in response to a variety of stimuli. However, in the present study, dexamethasone-treated TSM demonstrated similar isotonic shortening to control tissues upon ACh exposure, and the $4 \mu \mathrm{M}$ concentration of dexamethasone was chosen because it did not significantly affect isometric force in a separate cohort of TSM strips, suggesting that smooth muscle contractile activation was likely not impaired by dexamethasone. Glucocorticoids can also enhance smooth muscle relaxation by increasing adenylate cyclase activity [36], reducing $\beta_{2}$ receptor desensitisation [37], increasing the number of $\beta_{2}$ receptors [38] and increasing $\mathrm{Na}^{+} / \mathrm{K}^{+}$pump activity [19]. The latter effect, in particular, may be relevant because it occurs in $<1 \mathrm{~h}$. Corticosteroids can also reduce smooth muscle proliferation [39-41], although one might not expect change in cell number to be relevant within the short time-course of the current experiments.

Numerous studies have demonstrated that corticosteroids increase the expression of dual-specific phosphatases, especially MKP-1 [21-23], and by doing so decrease p38 MAPK activity, which is dephosphorylated and inactivated by MKP-1 [21]. It has previously been demonstrated that when p38 MAPK activity is inhibited pharmacologically with SB203580, FFIR of smooth muscle is enhanced [14]. In the present study, CTSM cells incubated with dexamethasone demonstrated increased MKP-1 expression within $1 \mathrm{~h}$ and decreased HSP27 phosphorylation by $2 \mathrm{~h}$. HSP27 is a well-established downstream phosphorylation target of p38 MAPK signalling [42, 43]; thus, the current data strongly suggest that dexamethasone treatment suppresses p38 MAPK activity. HSP27 is also an actin-capping protein that, when phosphorylated, promotes actin polymerisation [43-45]. Inhibition of HSP27 phosphorylation could be expected to decrease actin polymerisation; it was previously demonstrated that inhibition of actin polymerisation with latrunculin B increases FFIR $[17,46]$. Thus, the current authors propose that dexamethasone may enhance FFIR of contracted TSM by inducing MKP-1 expression, which in turn reduces p38 MAPK activation and HSP27 phosphorylation.

It is noteworthy that the effect of dexamethasone on the ability of contracted airway smooth muscle to maintain shortening was revealed through a loading protocol that simulates physiological conditions. This effect would otherwise not have been apparent, had only isotonic shortening or isometric force been measured. Thus, most traditional studies of muscle contractility have not considered the physiological pathways and mechanisms that are evoked here.
In conclusion, corticosteroids enhance force fluctuationinduced relengthening in contracted airway smooth muscle and inhibit the p38 mitogen-activated protein kinase pathway. Previous studies have demonstrated the importance of deep breaths in reversing bronchoconstriction and that this phenomenon is impaired in asthma but restored by corticosteroid treatment. The present study suggests that force fluctuationinduced relengthening is a mechanism by which deep inspirations protect against bronchoconstriction and that corticosteroids may restore this effect that is impaired in asthma, through inhibition of the p38 mitogen-activated protein kinase pathway and augmentation of force fluctuationinduced relengthening. These results suggest that novel therapies that enhance force fluctuation-induced relengthening, perhaps by targeting p38 mitogen-activated protein kinase, may have a beneficial effect in asthma.

\section{ACKNOWLEDGEMENTS}

The authors would like to thank W.T. Gerthoffer (Dept of Biochemistry, University of South Alabama, Mobile, AL, USA) for the HSP27 antibody.

\section{REFERENCES}

1 Shen X, Gunst SJ, Tepper RS. Effect of tidal volume and frequency on airway responsiveness in mechanically ventilated rabbits. J Appl Physiol 1997; 83: 1202-1208.

2 Salerno FG, Shinozuka N, Fredberg JJ, Ludwig MS. Tidal volume amplitude affects the degree of induced bronchoconstriction in dogs. J Appl Physiol 1999; 87: 1674-1677.

3 Murphy TM, Ray DW, Alger LE, et al. Ontogeny of dry gas hyperpnea-induced bronchoconstriction in guinea pigs. $J$ Appl Physiol 1994; 76: 1150-1155.

4 Freedman S, Lane R, Gillett MK, Guz A. Abolition of methacholine induced bronchoconstriction by the hyperventilation of exercise or volition. Thorax 1988; 43: 631-636.

5 Brown R, Mitzner W. Effects of tidal volume stretch on airway constriction in vivo. J Appl Physiol 2001; 91: 1995-1998.

6 Sly PD, Collins RA, Thamrin C, Turner DJ, Hantos Z. Volume dependence of airway and tissue impedances in mice. J Appl Physiol 2003; 94: 1460-1466.

7 Scichilone N, Permutt S, Togias A. The lack of the bronchoprotective and not the bronchodilatory ability of deep inspiration is associated with airway hyperresponsiveness. Am J Respir Crit Care Med 2001; 163: 413-419.

8 Skloot G, Togias A. Bronchodilation and bronchoprotection by deep inspiration and their relationship to bronchial hyperresponsiveness. Clin Rev Allergy Immunol 2003; 24: 55-72.

9 Kim J, McKinley L, Siddiqui J, Bolgos GL, Remick DG. Prevention and reversal of pulmonary inflammation and airway hyperresponsiveness by dexamethasone treatment in a murine model of asthma induced by house dust. Am J Physiol Lung Cell Mol Physiol 2004; 287: L503-L509.

10 Trifilieff A, El-Hashim A, Bertrand C. Time course of inflammatory and remodeling events in a murine model of asthma: effect of steroid treatment. Am J Physiol Lung Cell Mol Physiol 2000; 279: L1120-L1128.

11 Slats AM, Sont JK, van Klink RH, Bel EH, Sterk PJ. Improvement in bronchodilation following deep inspiration 
after a course of high-dose oral prednisone in asthma. Chest 2006; 130: 58-65.

12 Lim TK, Ang SM, Rossing TH, Ingenito EP, Ingram RH Jr. The effects of deep inhalation on maximal expiratory flow during intensive treatment of spontaneous asthmatic episodes. Am Rev Respir Dis 1989; 140: 340-343.

13 Corsico A, Pellegrino R, Zoia MC, Barbano L, Brusasco V, Cerveri I. Effects of inhaled steroids on methacholineinduced bronchoconstriction and gas trapping in mild asthma. Eur Respir J 2000; 15: 687-692.

14 Lakser OJ, Lindeman RP, Fredberg JJ. Inhibition of the p38 MAP kinase pathway destabilizes smooth muscle length during physiological loading. Am J Physiol Lung Cell Mol Physiol 2002; 282: L1117-L1121.

15 Fredberg JJ, Inouye D, Miller B, et al. Airway smooth muscle, tidal stretches, and dynamically determined contractile states. Am J Respir Crit Care Med 1997; 156: 1752-1759.

16 Fredberg JJ, Inouye DS, Mijailovich SM, Butler JP. Perturbed equilibrium of myosin binding in airway smooth muscle and its implications in bronchospasm. Am J Respir Crit Care Med 1999; 159: 959-967.

17 Dowell ML, Lakser OJ, Gerthoffer WT, et al. Latrunculin B increases force fluctuation-induced relengthening of AChcontracted, isotonically shortened canine tracheal smooth muscle. J Appl Physiol 2005; 98: 489-497.

18 Hakonarson H, Halapi E, Whelan R, Gulcher J, Stefansson K, Grunstein MM. Association between IL-1 $\beta /$ TNF- $\alpha$ induced glucocorticoid-sensitive changes in multiple gene expression and altered responsiveness in airway smooth muscle. Am J Respir Cell Mol Biol 2001; 25: 761-771.

19 Schramm CM, Grunstein MM. Corticosteroid modulation of $\mathrm{Na}^{+}-\mathrm{K}^{+}$pump-mediated relaxation in maturing airway smooth muscle. Br J Pharmacol 1996; 119: 807-812.

20 Schramm CM. $\beta$-Adrenergic relaxation of rabbit tracheal smooth muscle: a receptor deficit that improves with corticosteroid administration. J Pharmacol Exp Ther 2000; 292: 280-287.

21 Lasa M, Abraham SM, Boucheron C, Saklatvala J, Clark AR. Dexamethasone causes sustained expression of mitogen-activated protein kinase (MAPK) phosphatase 1 and phosphatase-mediated inhibition of MAPK p38. Mol Cell Biol 2002; 22: 7802-7811.

22 Engelbrecht $Y$, de Wet H, Horsch K, Langeveldt CR, Hough FS, Hulley PA. Glucocorticoids induce rapid up-regulation of mitogen-activated protein kinase phosphatase-1 and dephosphorylation of extracellular signal-regulated kinase and impair proliferation in human and mouse osteoblast cell lines. Endocrinology 2003; 144: 412-422.

23 Kassel O, Sancono A, Krätzschmar J, Kreft B, Stassen M, Cato AC. Glucocorticoids inhibit MAP kinase via increased expression and decreased degradation of MKP-1. EMBO J 2001; 20: 7108-7116.

24 Hedges JC, Dechert MA, Yamboliev IA, et al. A role for p38(MAPK)/HSP27 pathway in smooth muscle cell migration. J Biol Chem 1999; 274: 24211-24219.

25 Halayko AJ, Camoretti-Mercado B, Forsythe SM, et al. Divergent differentiation paths in airway smooth muscle culture: induction of functionally contractile myocytes. Am J Physiol 1999; 276: L197-L206.
26 Halayko AJ, Salari H, Ma X, Stephens NL. Markers of airway smooth muscle cell phenotype. Am J Physiol 1996; 270: L1040-L1051.

27 Mitchell RW, Halayko AJ, Kahraman S, Solway J, Wylam ME. Selective restoration of calcium coupling to muscarinic $\mathrm{M}_{3}$ receptors in contractile cultured airway myocytes. Am J Physiol Lung Cell Mol Physiol 2000; 278: L1091-L1100.

28 Kanefsky J, Lenburg M, Hai CM. Cholinergic receptor and cyclic stretch-mediated inflammatory gene expression in intact ASM. Am J Respir Cell Mol Biol 2006; 34: 417-425.

29 Hasaneen NA, Zucker S, Cao J, Chiarelli C, Panettieri RA, Foda HD. Cyclic mechanical strain-induced proliferation and migration of human airway smooth muscle cells: role of EMMPRIN and MMPs. FASEB J 2005; 19: 1507-1509.

30 Kumar A, Knox AJ, Boriek AM. CCAAT/enhancerbinding protein and activator protein-1 transcription factors regulate the expression of interleukin- 8 through the mitogen-activated protein kinase pathways in response to mechanical stretch of human airway smooth muscle cells. J Biol Chem 2003; 278: 18868-18876.

31 Quante T, Ng YC, Ramsay EE, et al. Corticosteroids reduce IL-6 in ASM cells via up-regulation of MKP-1. Am J Respir Cell Mol Biol 2008; 39: 208-217.

32 Hirst SJ, Lee TH. Airway smooth muscle as a target of glucocorticoid action in the treatment of asthma. Am J Respir Crit Care Med 1998; 158: S201-S206.

33 Tanaka H, Watanabe K, Tamaru N, Yoshida M. Arachidonic acid metabolites and glucocorticoid regulatory mechanism in cultured porcine tracheal smooth muscle cells. Lung 1995; 173: 347-361.

34 Hardy E, Farahani M, Hall IP. Regulation of histamine H1 receptor coupling by dexamethasone in human cultured airway smooth muscle. Br J Pharmacol 1996; 118: 1079-1084.

35 Nabishah BM, Morat PB, Kadir BA, Khalid BA. Effect of steroid hormones on muscarinic receptors of bronchial smooth muscle. Gen Pharmacol 1991; 22: 389-392.

36 Michel MC, Knapp J, Ratjen H. Sensitization by dexamethasone of lymphocyte cyclic AMP formation: evidence for increased function of the adenylyl cyclase catalyst. $\mathrm{Br} \mathrm{J}$ Pharmacol 1994; 113: 240-246.

37 Mak JC, Nishikawa M, Shirasaki H, Miyayasu K, Barnes PJ. Protective effects of a glucocorticoid on downregulation of pulmonary $\beta_{2}$-adrenergic receptors in vivo. J Clin Invest 1995; 96: 99-106.

38 Mak JC, Nishikawa M, Barnes PJ. Glucocorticosteroids increase $\beta_{2}$-adrenergic receptor transcription in human lung. Am J Physiol 1995; 268: L41-L46.

39 Young PG, Skinner SJ, Black PN. Effects of glucocorticoids and $\beta$-adrenoceptor agonists on the proliferation of airway smooth muscle. Eur J Pharmacol 1995; 273: 137-143.

40 Burgess JK, Lee JH, Ge Q, et al. Dual ERK and phosphatidylinositol 3-kinase pathways control airway smooth muscle proliferation: differences in asthma. J Cell Physiol 2008; 216: 673-679.

41 Roth $\mathrm{M}$, Johnson PR, Borger $\mathrm{P}$, et al. Dysfunctional interaction of $\mathrm{C} / \mathrm{EBP} \alpha$ and the glucocorticoid receptor in asthmatic bronchial smooth-muscle cells. N Engl J Med 2004; 351: 560-574.

42 Larsen JK, Yamboliev IA, Weber LA, Gerthoffer WT. Phosphorylation of the $27-\mathrm{kDa}$ heat shock protein via p38 
MAP kinase and MAPKAP kinase in smooth muscle. Am J Physiol 1997; 273: L930-L940.

43 Wang P, Bitar KN. Rho A regulates sustained smooth muscle contraction through cytoskeletal reorganization of HSP27. Am J Physiol 1998; 275: G1454-G1462.

44 Ibitayo AI, Sladick J, Tuteja S, et al. HSP27 in signal transduction and association with contractile proteins in smooth muscle cells. Am J Physiol 1999; 277: G445-G454.
45 Yamada H, Strahler J, Welsh MJ, Bitar KN. Activation of MAP kinase and translocation with HSP27 in bombesininduced contraction of rectosigmoid smooth muscle. Am J Physiol 1995; 269: G683-G691.

46 Fernandes DJ, Mitchell RW, Lakser O, Dowell M, Stewart AG, Solway J. Do inflammatory mediators influence the contribution of airway smooth muscle contraction to airway hyperresponsiveness in asthma? J Appl Physiol 2003; 95: 844-853. 